\title{
Fixed Point of $T$-Hardy-Rogers Contractive Mappings in Partially Ordered Partial Metric Spaces
}

\author{
Mujahid Abbas, ${ }^{1}$ Hassen Aydi, ${ }^{2}$ and Stojan Radenovic ${ }^{3}$ \\ ${ }^{1}$ Department of Mathematics, Lahore University of Management Sciences, Lahore 54792, Pakistan \\ ${ }^{2}$ Institut Supérieur d'Informatique et de Technologies de Communication de Hammam Sousse, \\ Université de Sousse, Route GP1, 4011 Hammam Sousse, Tunisia \\ ${ }^{3}$ Faculty of Mechanical Engineering, University of Belgrade, Kraljice Marije 16, 11120 Beograd, Serbia \\ Correspondence should be addressed to Stojan Radenović, sradenovic@mas.bg.ac.rs
}

Received 20 March 2012; Accepted 29 August 2012

Academic Editor: Brigitte Forster-Heinlein

Copyright (C 2012 Mujahid Abbas et al. This is an open access article distributed under the Creative Commons Attribution License, which permits unrestricted use, distribution, and reproduction in any medium, provided the original work is properly cited.

We prove some fixed point theorems for a T-Hardy-Rogers contraction in the setting of partially ordered partial metric spaces. We apply our results to study periodic point problems for such mappings. We also provide examples to illustrate the results presented herein.

\section{Introduction and Preliminaries}

The notion of a partial metric space was introduced by Matthews in [1]. In partial metric spaces, the distance of a point in the self may not be zero. After the definition of a partial metric space, Matthews proved the partial metric version of Banach fixed point theorem. A motivation behind introducing the concept of a partial metric was to obtain appropriate mathematical models in the theory of computation and, in particular, to give a modified version of the Banach contraction principle, more suitable in this context [1]. Subsequently, several authors studied the problem of existence and uniqueness of a fixed point for mappings satisfying different contractive conditions (e.g., [2-21], [22]). Existence of fixed points in partially ordered metric spaces has been initiated in 2004 by Ran and Reurings [23]. Subsequently, several interesting and valuable results have appeared in this direction [14]. The aim of this paper is to study the necessary conditions for existence of fixed point of mapping satisfying $T$-Hardy-Rogers conditions in the framework of partially ordered partial metric spaces. Our results extend and strengthen various known results $[8,24]$. In the sequel, the letters $\mathbb{R}, \mathbb{R}^{+}$, and $\mathbb{N}$ will denote the set of real numbers, the set of nonnegative real 
numbers, and the set of nonnegative integer numbers, respectively. The usual order on $\mathbb{R}$ (resp., on $\mathbb{R}^{+}$) will be indistinctly denoted by $\leq$or by $\geq$.

Consistent with $[1,8]$ (see [25-29]) the following definitions and results will be needed in the sequel.

Definition 1.1 (see [1]). A partial metric on a nonempty set $X$ is a mapping $p: X \times X \rightarrow \mathbb{R}^{+}$ such that for all $x, y, z \in X$,

$$
\begin{aligned}
& \left(p_{1}\right) x=y \Leftrightarrow p(x, x)=p(x, y)=p(y, y) \\
& \left(p_{2}\right) p(x, x) \leq p(x, y) \\
& \left(p_{3}\right) p(x, y)=p(y, x) \\
& \left(p_{4}\right) p(x, y) \leq p(x, z)+p(z, y)-p(z, z) .
\end{aligned}
$$

A partial metric space is a pair $(X, p)$ such that $X$ is a nonempty set and $p$ is a partial metric on $X$. If $p(x, y)=0$, then $\left(p_{1}\right)$ and $\left(p_{2}\right)$ imply that $x=y$. But converse does not hold always. A trivial example of a partial metric space is the pair $\left(\mathbb{R}^{+}, p\right)$, where $p: \mathbb{R}^{+} \times \mathbb{R}^{+} \rightarrow \mathbb{R}^{+}$is defined as $p(x, y)=\max \{x, y\}$. Each partial metric $p$ on $X$ generates a $T_{0}$ topology $\tau_{p}$ on $X$ which has as a base the family open $p$-balls $\left\{B_{p}(x, \varepsilon): x \in X, \varepsilon>0\right\}$, where $B_{p}(x, \varepsilon)=\{y \in X: p(x, y)<$ $p(x, x)+\varepsilon\}$.

On a partial metric space the concepts of convergence, Cauchy sequence, completeness, and continuity are defined as follows.

Definition 1.2 (see [1]). Let $(X, p)$ be a partial metric space and let $\left\{x_{n}\right\}$ be a sequence in $X$. Then (i) $\left\{x_{n}\right\}$ converges to a point $x \in X$ if and only if $p(x, x)=\lim _{n \rightarrow \infty} p\left(x, x_{n}\right)$ (we may still write this as $\lim _{n \rightarrow \infty} x_{n}=v$ or $x_{n} \rightarrow v$ ); (ii) $\left\{x_{n}\right\}$ is called a Cauchy sequence if there exists (and is finite) $\lim _{n, m \rightarrow \infty} p\left(x_{n}, x_{m}\right)$.

Definition 1.3 (see [1]). A partial metric space $(X, p)$ is said to be complete if every Cauchy sequence $\left\{x_{n}\right\}$ in $X$ converges to a point $x \in X$, such that $p(x, x)=\lim _{n, m \rightarrow \infty} p\left(x_{n}, x_{m}\right)$. If $p$ is a partial metric on $X$, then the function $p^{s}: X \times X \rightarrow R^{+}$given by $p^{s}(x, y)=2 p(x, y)-$ $p(x, x)-p(y, y)$ is a metric on $X$.

Lemma 1.4 (see $[1,20])$. Let $(X, p)$ be a partial metric space. Then

(a) $\left\{x_{n}\right\}$ is a Cauchy sequence in $(X, p)$ if and only if it is a Cauchy sequence in the metric $\operatorname{space}\left(X, p^{s}\right)$;

(b) $(X, p)$ is complete if and only if the metric space $\left(X, p^{s}\right)$ is complete. Furthermore, $\lim _{n \rightarrow \infty} p^{s}\left(x_{n}, x\right)=0$ if and only if

$$
p(x, x)=\lim _{n \rightarrow \infty} p\left(x_{n}, x\right)=\lim _{n, m \rightarrow \infty} p\left(x_{n}, x_{m}\right) .
$$

Remark 1.5. (1) (see [19]) Clearly, a limit of a sequence in a partial metric space does not need to be unique. Moreover, the function $p(\cdot, \cdot)$ does not need to be continuous in the sense that $x_{n} \rightarrow x$ and $y_{n} \rightarrow y$ implies $p\left(x_{n}, y_{n}\right) \rightarrow p(x, y)$. For example, if $X=[0,+\infty)$ and $p(x, y)=\max \{x, y\}$ for $x, y \in X$, then for $\left\{x_{n}\right\}=\{1\}, p\left(x_{n}, x\right)=x=p(x, x)$ for each $x \geq 1$ and so, for example, $x_{n} \rightarrow 2$ and $x_{n} \rightarrow 3$ when $n \rightarrow \infty$.

(2) (see [7]) However, if $p\left(x_{n}, x\right) \rightarrow p(x, x)=0$ then $p\left(x_{n}, y\right) \rightarrow p(x, y)$ for all $y \in X$. 
Definition 1.6 (see [30]). Suppose that $(X, p)$ is a partial metric space. Denote $\tau(p)$ its topology. We say $T:(X, p) \rightarrow(X, p)$ is continuous if both $T:(X, \tau(p)) \rightarrow(X, \tau(p))$ and $T:$ $\left(X, \tau\left(p^{s}\right)\right) \rightarrow\left(X_{2}, \tau\left(p^{s}\right)\right)$ are continuous.

Remark 1.7. It is worth to notice that the notions $p$-continuous and $p^{s}$-continuous of any function in the context of partial metric spaces are incomparable, in general. Indeed, if $X=[0,+\infty), p(x, y)=\max \{x, y\}, p^{s}(x, y)=|x-y|, f 0=1$, and $f x=x^{2}$ for all $x>0$ and $g x=|\sin x|$, then $f$ is a $p$-continuous and $p^{s}$-discontinuous at point $x=0$; while $g$ is a $p$-discontinuous and $p^{s}$-continuous at $x=\pi$.

According to [31], we state the following definition.

Definition 1.8. Let $(X, p)$ be a partial metric space. A mapping $T: X \rightarrow X$ is said to be

(i) sequentially convergent if for any sequence $\left\{y_{n}\right\}$ in $X$ such that $\left\{T y_{n}\right\}$ is convergent in $\left(X, p^{s}\right)$ implies that $\left\{y_{n}\right\}$ is convergent in $\left(X, p^{s}\right)$,

(ii) subsequentially convergent if for any sequence $\left\{y_{n}\right\}$ in $X$ such that $\left\{T y_{n}\right\}$ is convergent in $\left(X, p^{s}\right)$ implies that $\left\{y_{n}\right\}$ has a convergent subsequence in $\left(X, p^{s}\right)$.

Consistent with $[24,31]$ we define a $T$-Hardy-Rogers contraction in the framework of partial metric spaces.

Definition 1.9. Let $(X, p)$ be a partial metric space and $T, f: X \rightarrow X$ be two mappings. A mapping $f$ is said to be a $T$-Hardy-Rogers contraction if there exist $a_{i} \geq 0, i=1, \ldots, 5$ with $a_{1}+a_{2}+a_{3}+a_{4}+a_{5}<1$ such that for all $x, y \in X$

$$
\begin{aligned}
p(T f x, T f y) \leq & a_{1} p(T x, T y)+a_{2} p(T x, T f x)+a_{3} p(T y, T f y) \\
& +a_{4} p(T x, T f y)+a_{5} p(T y, T f x) .
\end{aligned}
$$

Putting $a_{1}=a_{4}=a_{5}=0$ and $a_{2}=a_{3} \neq 0$, (resp., $a_{1}=a_{2}=a_{3}=0$ and $a_{4}=a_{5} \neq 0$ ) in the previous definition, then the inequality (1.2) is said a $T$-Kannan (resp., $T$-Chatterjea) type contraction. Also, if $a_{4}=a_{5}=0$ and $a_{1}, a_{2}, a_{3} \neq 0,(1.2)$ is said the T-Reich type contraction.

Definition 1.10. Let $X$ be a nonempty set. Then $(X, p, \preceq)$ is called a partially ordered partial metric space if and only if (i) $p$ is a partial metric on $X$ and (ii) $\preceq$ is a partial order on $X$.

Let $(X, p)$ be a partial metric space endowed with a partial order $\leq$ and let $f: X \rightarrow X$ be a given mapping. We define sets $\Delta, \Delta_{1} \subset X \times X$ by

$$
\begin{gathered}
\Delta=\{(x, y) \in X \times X: x \leq y \text { or } y \leq x\}, \\
\Delta_{1}=\{(x, x) \in X \times X: x \leq f x \text { or } f x \preceq x\} .
\end{gathered}
$$

A point $x \in X$ is called a fixed point of mapping $f: X \rightarrow X$ if $x=f x$. The set of all fixed points of the mapping $f$ is denoted by $F_{f}$. 


\section{Fixed Point Results}

In this section, we obtain fixed point results for a mapping satisfying a $T$-Hardy-Rogers contractive condition defined on a partially ordered partial metric space which is complete.

We start with the following result.

Theorem 2.1. Let $(X, \leq, p)$ be an partially ordered partial metric space which is complete. Let $T$ : $X \rightarrow X$ be a continuous, injective mapping and $f: X \rightarrow X$ a nondecreasing $T$-Hardy-Rogers contraction for all $(x, y) \in \Delta$. If there exists $x_{0} \in X$ with $x_{0} \leq f x_{0}$, and one of the following two conditions is satisfied

(a) $f$ is a continuous self-map on $X$;

(b) for any nondecreasing sequence $\left\{x_{n}\right\}$ in $(X, \preceq)$ with $\lim _{n \rightarrow \infty} p^{s}\left(z, x_{n}\right)=0$ it follows $x_{n} \preceq$ $z$ for all $n \in \mathbb{N}$;

then $F_{f} \neq \phi$ provided that $T$ is subsequentially or sequentially convergent. Moreover, $f$ has a unique fixed point if $F_{f} \times F_{f} \subset \Delta$.

Proof. As $f$ is nondecreasing, therefore by given assumption, we have

$$
x_{1}=f x_{0} \leq f^{2} x_{0} \leq \cdots \leq f^{n} x_{0} \leq f^{n+1} x_{0} \leq \cdots
$$

Define a sequence $\left\{x_{n}\right\}$ in $X$ with $x_{n}=f^{n} x_{0}$ and so $x_{n+1}=f x_{n}$ for $n \in \mathbb{N}$. Since $\left(x_{n-1}, x_{n}\right) \in \Delta$ therefore by replacing $x$ by $x_{n-1}$ and $y$ by $x_{n}$ in (1.2), we have

$$
\begin{aligned}
p\left(T x_{n}, T x_{n+1}\right)= & p\left(T f x_{n-1}, T f x_{n}\right) \\
\leq & a_{1} p\left(T x_{n-1}, T x_{n}\right)+a_{2} p\left(T x_{n-1}, T f x_{n-1}\right)+a_{3} p\left(T x_{n}, T f x_{n}\right) \\
& +a_{4} p\left(T x_{n-1}, T f x_{n}\right)+a_{5} p\left(T x_{n}, T f x_{n-1}\right) \\
= & a_{1} p\left(T x_{n-1}, T x_{n}\right)+a_{2} p\left(T x_{n-1}, T x_{n}\right)+a_{3} p\left(T x_{n}, T x_{n+1}\right) \\
& +a_{4} p\left(T x_{n-1}, T x_{n+1}\right)+a_{5} p\left(T x_{n}, T x_{n}\right) \\
\leq & \left(a_{1}+a_{2}\right) p\left(T x_{n-1}, T x_{n}\right)+a_{3} p\left(T x_{n}, T x_{n+1}\right) \\
& +a_{4}\left[p\left(T x_{n-1}, T x_{n}\right)+p\left(T x_{n}, T x_{n+1}\right)-p\left(T x_{n}, T x_{n}\right)\right]+a_{5} p\left(T x_{n}, T x_{n}\right) \\
= & \left(a_{1}+a_{2}+a_{4}\right) p\left(T x_{n-1}, T x_{n}\right)+\left(a_{3}+a_{4}\right) p\left(T x_{n}, T x_{n+1}\right) \\
& +\left(a_{5}-a_{4}\right) p\left(T x_{n}, T x_{n}\right),
\end{aligned}
$$

that is,

$$
\left(1-a_{3}-a_{4}\right) p\left(T x_{n}, T x_{n+1}\right) \leq\left(a_{1}+a_{2}+a_{4}\right) p\left(T x_{n-1}, T x_{n}\right)+\left(a_{5}-a_{4}\right) p\left(T x_{n}, T x_{n}\right) .
$$

Similarly, replacing $x$ by $x_{n}$ and $y$ by $x_{n-1}$ in (1.2), we obtain

$$
\left(1-a_{2}-a_{5}\right) p\left(T x_{n}, T x_{n+1}\right) \leq\left(a_{1}+a_{3}+a_{5}\right) p\left(T x_{n-1}, T x_{n}\right)+\left(a_{4}-a_{5}\right) p\left(T x_{n}, T x_{n}\right) .
$$


Summing (2.3) and (2.4), we obtain $p\left(T x_{n}, T x_{n+1}\right) \leq \delta p\left(T x_{n-1}, T x_{n}\right)$, where $\delta=\left(2 a_{1}+a_{2}+\right.$ $\left.a_{3}+a_{4}+a_{5}\right) /\left(2-a_{2}-a_{3}-a_{4}-a_{5}\right)$. Obviously $0 \leq \delta<1$. Therefore, for all $n \geq 1$,

$$
p\left(T x_{n}, T x_{n+1}\right) \leq \delta p\left(T x_{n-1}, T x_{n}\right) \leq \cdots \leq \delta^{n} p\left(T x_{0}, T x_{1}\right)
$$

Now, for any $m \in N$ with $m>n$, we have

$$
\begin{aligned}
p\left(T x_{n}, T x_{m}\right) & \leq p\left(T x_{n}, T x_{n+1}\right)+p\left(T x_{n+1}, T x_{n+2}\right)+\cdots+p\left(T x_{m-1}, T x_{m}\right) \\
& \leq\left(\delta^{n}+\delta^{n+1}+\cdots+\delta^{m-1}\right) p\left(T x_{0}, T x_{1}\right) \leq \frac{\delta^{n}}{1-\delta} p\left(T x_{0}, T x_{1}\right)
\end{aligned}
$$

which implies that $p\left(T x_{n}, T x_{m}\right) \rightarrow 0$ as $n, m \rightarrow \infty$. Hence $\left\{T x_{n}\right\}$ is a Cauchy sequence in $(X, p)$ and in $\left(X, p^{s}\right)$. Since $(X, p)$ is complete, therefore from Lemma $1.4,\left(X, p^{s}\right)$ is a complete metric space. Hence $\left\{T x_{n}\right\}$ converges to some $v \in X$ with respect to the metric $p^{s}$, that is,

$$
\lim _{n \rightarrow \infty} p^{s}\left(T x_{n}, v\right)=0
$$

or equivalently,

$$
p(v, v)=\lim _{n \rightarrow \infty} p\left(T x_{n}, v\right)=\lim _{n, m \rightarrow \infty} p\left(T x_{n}, T x_{m}\right)=0
$$

Suppose that $T$ is subsequentially convergent, therefore convergence of $\left\{T x_{n}\right\}$ in $\left(X, p^{s}\right)$ implies that $\left\{x_{n}\right\}$ has a convergent subsequence $\left\{x_{n_{i}}\right\}$ in $\left(X, p^{s}\right)$. So

$$
\lim _{i \rightarrow \infty} p^{s}\left(x_{n_{i}}, u\right)=0 \text {, }
$$

for some $u \in X$. As $T$ is continuous, so (2.9) and Definition 1.6. imply that $\lim _{i \rightarrow \infty} p^{s}$ $\left(T x_{n_{i}}, T u\right)=0$. From $(2.7)$ and by the uniqueness of the limit in metric space $\left(X, p^{s}\right)$, we obtain $T u=v$. Consequently,

$$
0=p(T u, T u)=\lim _{i \rightarrow \infty} p\left(T x_{n_{i}}, T u\right)=\lim _{i, j \rightarrow \infty} p\left(T x_{n_{i}}, T x_{n_{j}}\right) .
$$

$\left(1^{\circ}\right)$ If $f$ is a continuous self-map on $X$, then $f x_{n_{i}} \rightarrow f u$ and $T f x_{n_{i}} \rightarrow T f u$ as $i \rightarrow \infty$. Since $T x_{n_{i}} \rightarrow T u$ as $i \rightarrow \infty$, we obtain that $T f u=T u$. As $T$ is injective, so we have $f u=u$.

$\left(2^{\circ}\right)$ If $f$ is not continuous then by given assumption we have $x_{n} \leq u$ for all $n \in \mathbb{N}$. Thus for a subsequence $\left\{x_{n_{i}}\right\}$ of $\left\{x_{n}\right\}$ we have $x_{n_{i}} \leq u$ and $\left(x_{n_{i}}, u\right) \in \Delta$. Now,

$$
\begin{aligned}
p(T f u, T u) \leq & p\left(T f u, T f x_{n_{i}}\right)+p\left(T f x_{n_{i}}, T u\right)-p\left(T f x_{n_{i}}, T f x_{n_{i}}\right) \\
\leq & a_{1} p\left(T x_{n_{i}}, T u\right)+a_{2} p\left(T x_{n_{i}}, T f x_{n_{i}}\right)+a_{3} p(T u, T f u)+a_{4} p\left(T x_{n_{i}}, T f u\right) \\
& +a_{5} p\left(T u, T f x_{n_{i}}\right)+p\left(T f x_{n_{i}}, T u\right)-p\left(T f x_{n_{i}}, T f x_{n_{i}}\right)
\end{aligned}
$$




$$
\begin{aligned}
= & a_{1} p\left(T x_{n_{i}}, T u\right)+a_{2} p\left(T x_{n_{i}}, T x_{n_{i}+1}\right)+a_{3} p(T u, T f u)+a_{4} p\left(T x_{n_{i}}, T f u\right) \\
& +a_{5} p\left(T u, T x_{n_{i}+1}\right)+p\left(T x_{n_{i}+1}, T u\right)-p\left(T x_{n_{i}+1}, T x_{n_{i}+1}\right) \\
\leq & a_{1} p\left(T x_{n_{i}}, T u\right)+a_{2} p\left(T x_{n_{i}}, T x_{n_{i}+1}\right)+a_{3} p(T u, T f u) \\
& +a_{4}\left[p\left(T x_{n_{i}}, T u\right)+p(T u, T f u)-p(T u, T u)\right]+a_{5} p\left(T u, T x_{n_{i}+1}\right) \\
& +p\left(T x_{n_{i}+1}, T u\right)-p\left(T x_{n_{i}+1}, T x_{n_{i}+1}\right) .
\end{aligned}
$$

On taking limit as $i \rightarrow \infty$ and applying Remark 1.5. (2) we get

$$
\begin{aligned}
p(T u, T f u) \leq & a_{1} p(T u, T u)+a_{2} p(T u, T u)+a_{3} p(T u, T f u) \\
& +a_{4}[p(T u, T u)+p(T u, T f u)-p(T u, T u)] \\
& +a_{5} p(T u, T u)+p(T u, T u)-p(T u, T u) \\
= & \left(a_{1}+a_{2}+a_{5}\right) p(T u, T u)+\left(a_{3}+a_{4}\right) p(T u, T f u) \\
\leq & \left(a_{1}+a_{2}+a_{3}+a_{4}+a_{5}\right) p(T u, T f u) \\
< & p(T u, T f u),
\end{aligned}
$$

which implies that $p(T u, T f u)=0$, and so $T u=T f u$. Now injectivity of $T$ gives $u=f u$. Following similar arguments to those given above, the result holds when $T$ is sequentially convergent.

Suppose that $F_{f} \times F_{f} \subset \Delta$. Let $w$ be a fixed point of $f$. As $F_{f} \times F_{f} \subset \Delta$, therefore $(u, w) \in \Delta$. From (1.2), we have

$$
\begin{aligned}
p(T u, T w) & =p(T f u, T f w) \\
& \leq a_{1} p(T u, T w)+a_{2} p(T u, T f u)+a_{3} p(T w, T f w)+a_{4} p(T u, T f w)+a_{5} p(T w, T f u) \\
& =a_{1} p(T u, T w)+a_{2} p(T u, T u)+a_{3} p(T w, T w)+a_{4} p(T u, T w)+a_{5} p(T w, T u) \\
& \leq\left(a_{1}+a_{2}+a_{3}+a_{3}+a_{4}+a_{5}\right) p(T u, T w) \\
& <p(T u, T w)
\end{aligned}
$$

and hence $p(T u, T w)=0$, which further implies that $u=w$ as $T$ is injective. 
Example 2.2. Let $X=[0,1]$ be endowed with usual order and let $p$ be the complete partial metric on $X$ defined by $p(x, y)=\max \{x, y\}$ for all $x, y \in X$. Let $T, f: X \rightarrow X$ be defined by $T x=4 x / 5$ and $f x=x / 4$. Note that $\Delta=X \times X$. For any $(x, y) \in \Delta$, we have

$$
\begin{aligned}
p(T f x, T f y)= & \max \left\{\frac{x}{5}, \frac{y}{5}\right\}=\frac{1}{5} \max \{x, y\} \leq \frac{12}{35} \max \{x, y\} \\
\leq & \frac{2}{7} \max \left\{\frac{4 x}{5}, \frac{4 y}{5}\right\}+\frac{1}{7} \max \left\{\frac{4 x}{5}, \frac{x}{5}\right\}+\frac{1}{7} \max \left\{\frac{4 y}{5}, \frac{y}{5}\right\} \\
& +\frac{1}{7} \max \left\{\frac{4 x}{5}, \frac{y}{5}\right\}+\frac{1}{7} \max \left\{\frac{4 y}{5}, \frac{x}{5}\right\} \\
= & a_{1} p(T x, T y)+a_{2} p(T x, T f x)+a_{3} p(T y, T f y) \\
& +a_{4} p(T x, T f y)+a_{5} p(T y, T f x) .
\end{aligned}
$$

Therefore, $f$ is a $T$-Hardly-Rogers contraction with $a_{1}=2 / 7, a_{2}=a_{3}=a_{4}=a_{5}=1 / 7$. Obviously, $T$ is continuous and sequentially convergent. Thus, all the conditions of Theorem 2.1 are satisfied. Moreover, 0 is the unique fixed point of $f$.

Example 2.3. Let $X=[0, \infty)$ be endowed with usual order and let $p$ be a partial metric on $X$ defined by $p(x, y)=\max \{x, y\}$ for all $x, y \in X$. Define $T, f: X \rightarrow X$ by $T x=x^{2}$ and $f x=$ $x / 3$. Note that $\Delta=X \times X$. For any $(x, y) \in \Delta$, we have

$$
\begin{aligned}
p(T f x, T f y)= & \max \left\{\frac{x^{2}}{9}, \frac{y^{2}}{9}\right\}=\frac{1}{9} \max \left\{x^{2}, y^{2}\right\} \leq \frac{1}{6} \max \left\{x^{2}, y^{2}\right\} \\
= & a_{1} p(T x, T y) \leq a_{1} p(T x, T y)+a_{2} p(T x, T f x)+a_{3} p(T y, T f y) \\
& +a_{4} p(T x, T f y)+a_{5} p(T y, T f x) .
\end{aligned}
$$

Therefore, $f$ is a $T$-Hardly-Rogers contraction with $a_{1}=a_{2}=a_{3}=a_{4}=a_{5}=1 / 6$. Also, $T$ is continuous and sequentially convergent. Thus all the conditions of Theorem 2.1 are satisfied. Moreover, 0 is the unique fixed point of $f$.

Taking $T x=x$ in (1.2) and Theorem 2.1, we get the Hardy-Rogers type [32] (and so the Kannan, Chatterjea, and Reich) fixed point theorem on partially ordered partial metric spaces.

Corollary 2.4. Let $(X, \preceq, p)$ be a partially ordered partial metric space which is complete. Let $f: X \rightarrow$ $X$ be a nondecreasing mapping such that for all $(x, y) \in \Delta$, we have

$$
p(f x, f y) \leq a_{1} p(x, y)+a_{2} p(x, f x)+a_{3} p(y, f y)+a_{4} p(x, f y)+a_{5} p(y, f x)
$$

where $a_{i} \geq 0, i=1, \ldots, 5$ with $a_{1}+a_{2}+a_{3}+a_{4}+a_{5}<1$. If there exists $x_{0} \in X$ with $x_{0} \leq f x_{0}$, and one of the following two conditions is satisfied.

(a) $f$ is a continuous self map on $X$;

(b) for any nondecreasing sequence $\left\{x_{n}\right\}$ in $(X, \preceq)$ with $\lim _{n \rightarrow \infty} p^{s}\left(z, x_{n}\right)=0$ it follows $x_{n} \preceq$ $z$ for all $n \in \mathbb{N}$; then $F_{f} \neq \phi$. Moreover, $f$ has a unique fixed point if $F_{f} \times F_{f} \subset \Delta$. 
Remark 2.5. Corollary 2.4 corresponds to Theorem 2 of Altun et al. [8] in partially ordered partial metric spaces. For particular choices of the coefficients $\left(a_{i}\right)_{i=1, \ldots, 5}$ in Theorem 2.1, we obtain the $T$-Kannan, $T$-Chatterjea, and $T$-Reich type fixed point theorems. Also, Theorem 2.1 is an extension of Theorem 2.1 of Filipović et al. [24] from the cone metric spaces to partial metric spaces.

\section{Periodic Point Results}

Let $f: X \rightarrow X$. If the map $f$ satisfies $F_{f}=F_{f^{n}}$ for each $n \in \mathbb{N}$, then it is said to have the property $P$, for more details see [33].

Definition 3.1. Let $(X, \preceq)$ be a partially ordered set. A mapping $f$ is called (1) a dominating map on $X$ if $x \leq f x$ for each $x$ in $X$ and (2) a dominated map on $X$ if $f x \leq x$ for each $x$ in $X$.

Example 3.2. Let $X=[0,1]$ be endowed with usual ordering. Let $f: X \rightarrow X$ defined by $f x=x^{1 / 3}$, then $x \leq x^{1 / 3}=f x$ for all $x \in X$. Thus $f$ is a dominating map.

Example 3.3. Let $X=[0, \infty)$ be endowed with usual ordering. Let $f: X \rightarrow X$ defined by $f x=\sqrt[n]{x}$ for $x \in[0,1)$ and let $f x=x^{n}$ for $x \in[1, \infty)$, for any $n \in \mathbb{N}$, then for all $x \in X$, $x \leq f x$ that is $f$ is the dominating map. Note that $\Delta_{1} \neq \phi$ if $f$ is a dominating or a dominated mapping.

We have the following result.

Theorem 3.4. Let $(X, \preceq, p)$ be a partially ordered partial metric space which is complete. Let $T: X \rightarrow$ $X$ be an injective mapping and $f: X \rightarrow X$ a nondecreasing such that for all $(x, x) \in \Delta_{1}$, we have

$$
p\left(T f x, T f^{2} x\right) \leq \lambda p(T x, T f x)
$$

for some $\lambda \in[0,1)$ and for all $x \in X, x \neq f x$. Then $f$ has the property $P$ provided that $F_{f}$ is nonempty and $f$ is a dominating map on $F_{f^{n}}$.

Proof. Let $u \in F_{f^{n}}$ for some $n>1$. Now we show that $u=f u$. Since $f$ is dominating on $F_{f^{n}}$, therefore $u \leq f u$ which further implies that $f^{n-1} u \leq f^{n} u$ as $f$ is nondecreasing. Hence $\left(f^{n-1} u, f^{n-1} u\right) \in \Delta_{1}$. Now by using (3.1), we have

$$
\begin{aligned}
p(T u, T f u) & =p\left(T f f^{n-1} u, T f^{2} f^{n-1} u\right) \\
& \leq \lambda p\left(T f^{n-1} u, T f^{n} u\right)=\lambda p\left(T f f^{n-2} u, T f^{2} f^{n-2} u\right)
\end{aligned}
$$

Repeating the above process, we get

$$
p(T u, T f u) \leq \lambda^{n} p(T u, T f u)
$$

Taking limit as $n \rightarrow \infty$, we obtain $p(T u, T f u)=0$ and $T u=T f u$. As $T$ is injective, so $u=f u$, that is, $u \in F_{f}$. 
International Journal of Mathematics and Mathematical Sciences

Theorem 3.5. Let $(X, \preceq, p)$ be a partially ordered partial metric space which is complete. let $T, f$ : $X \rightarrow X$ be mappings satisfy the condition of Theorem 2.1. If $f$ is dominating on $X$, then $f$ has the property $P$.

Proof. From Theorem 2.1, $F_{f} \neq \emptyset$. We will prove that (3.1) is satisfied for all $(x, x) \in \Delta_{1}$. Indeed, $f$ is a dominating map so that $x \preceq f x$ and also $f$ is nondecreasing so that $f x \preceq f^{2} x$ and hence $(x, f x) \in \Delta$. Now from (1.2),

$$
\begin{aligned}
p\left(T f x, T f^{2} x\right)= & p(T f x, T f f x) \leq a_{1} p(T x, T f x)+a_{2} p(T x, T f x)+a_{3} p\left(T f x, T f^{2} x\right) \\
& +a_{4} p\left(T x, T f^{2} x\right)+a_{5} p(T f x, T f x) \\
\leq & \left(a_{1}+a_{2}\right) p(T x, T f x)+a_{3} p\left(T f x, T f^{2} x\right) \\
& +a_{4}\left(p(T x, T f x)+p\left(T f x, T f^{2} x\right)-p(T f x, T f x)\right)+a_{5} p(T f x, T f x),
\end{aligned}
$$

that is,

$$
\left(1-a_{3}-a_{4}\right) p\left(T f x, T f^{2} x\right) \leq\left(a_{1}+a_{2}+a_{4}\right) p(T x, T f x)+\left(a_{5}-a_{4}\right) p(T f x, T f x) .
$$

Again by using (1.2), we have

$$
\begin{aligned}
p\left(T f^{2} x, T f x\right)= & p(T f f x, T f x) \leq a_{1} p(T f x, T x)+a_{2} p\left(T f x, T f^{2} x\right)+a_{3} p(T x, T f x) \\
& +a_{4} p(T f x, T f x)+a_{5} p\left(T x, T f^{2} x\right) \\
\leq & \left(a_{1}+a_{3}\right) p(T x, T f x)+a_{2} p\left(T f x, T f^{2} x\right)+a_{4} p(T f x, T f x) \\
& +a_{5}\left(p(T x, T f x)+p\left(T f x, T f^{2} x\right)-p(T f x, T f x)\right),
\end{aligned}
$$

which implies that

$$
\left(1-a_{2}-a_{5}\right) p\left(T f x, T f^{2} x\right) \leq\left(a_{1}+a_{3}+a_{5}\right) p(T x, T f x)+\left(a_{4}-a_{5}\right) p(T f x, T f x) .
$$

Summing (3.5) and (3.7) implies $p\left(T f x, T f^{2} x\right) \leq \lambda p(T x, T f x), \lambda=\left(2 a_{1}+a_{2}+a_{3}+a_{4}+a_{5}\right) /(2-$ $\left.a_{2}-a_{3}-a_{4}-a_{5}\right)$. Obviously, $\lambda \in[0,1)$. By Theorem 3.4, $f$ has the property $P$.

\section{Acknowledgment}

S. Radenović is thankful to The Ministry of Science and Technology Development of Serbia. 


\section{References}

[1] S. G. Matthews, "Partial metric topology," Annals of the New York Academy of Sciences, vol. 728, pp. 183-197, 1994.

[2] M. Abbas, T. Nazir, and S. Romaguera, "Fixed point results for generalized cyclic contraction mappings in partial metric spaces," Revista de la Real Academia de Ciencias Exactas, vol. 106, no. 2, pp. 287-297, 2012.

[3] T. Abdeljawad, "Fixed points for generalized weakly contractive mappings in partial metric spaces," Mathematical and Computer Modelling, vol. 54, no. 11-12, pp. 2923-2927, 2011.

[4] T. Abdeljawad, E. Karapinar, and K. Taş, "A generalized contraction principle with control functions on partial metric spaces," Computers and Mathematics with Applications, vol. 63, no. 3, pp. 716-719, 2012.

[5] P. R. Agarwal, A. M. Alghamdi, and N. Shahzad, "Fixed point theory for cyclic generalized contractions in partial metric spaces," Fixed Point Thewory and Applications, vol. 2012, p. 40, 2012.

[6] I. Altun and A. Erduran, "Fixed point theorems for monotone mappings on partial metric spaces," Fixed Point Theory and Applications, vol. 2011, Article ID 508730, 10 pages, 2011.

[7] T. Abdeljawad, E. Karapnar, and K. Taş, “Existence and uniqueness of a common fixed point on partial metric spaces," Applied Mathematics Letters, vol. 24, no. 11, pp. 1900-1904, 2011.

[8] I. Altun, F. Sola, and H. Simsek, "Generalized contractions on partial metric spaces," Topology and its Applications, vol. 157, no. 18, pp. 2778-2785, 2010.

[9] H. Aydi, "Some coupled fixed point results on partial metric spaces," International Journal of Mathematics and Mathematical Sciences, vol. 2011, Article ID 647091, 11 pages, 2011.

[10] H. Aydi, "Fixed point results for weakly contractive mappings in ordered partial metric spaces," Journal of Advanced Mathematical Studies, vol. 4, no. 2, pp. 1-12, 2011.

[11] H. Aydi, "Fixed point theorems for generalized weakly contractive condition in ordered partial metric spaces," Journal of Nonlinear Analysis and Optimization: Theory and Applications, vol. 2, no. 2, pp. 33-48, 2011.

[12] L. Ćirić, B. Samet, H. Aydi, and C. Vetro, "Common fixed points of generalized contractions on partial metric spaces and an application," Applied Mathematics and Computation, vol. 218, pp. 2398-2406, 2011.

[13] C. Di Bari and P. Vetro, "Fixed points for weak $\phi$-contractions on partial metric spaces," International Journal of Engineering, Contemporary Mathematics and Sciences, vol. 1, no. 1, pp. 4-9, 2011.

[14] D. Dukić, Z. Kadelburg, and S. Radenović, "Fixed point of Geraghty-type mappings in various generalized metric spaces," Abstract and Applied Analysis, vol. 2011, Article ID Article ID 561245, 13 pages, 2011.

[15] D. Ilić, V. Pavlović, and V. Rakočević, "Some new extensions of Banach's contractions principle in partial metric spaces," Applied Mathematics Letters, vol. 24, no. 8, pp. 1326-1330, 2011.

[16] D. Ilić, V. Pavlović, and V. Rakočević, "Extensions of Zamfirescu theorem to partial metric spaces," Mathematical and Computer Modelling, vol. 55, no. 3-4, pp. 801-809, 2012.

[17] E. Karapnar and I. M. Erhan, "Fixed point theorems for operators on partial metric spaces," Applied Mathematics Letters, vol. 24, no. 11, pp. 1894-1899, 2011.

[18] N. Hussain, Z. Kadelburg, and S. Radenović, "Comparison functions and fixed point results in partial metric spaces," Abstrac and Applied Analysis, vol. 2012, Article ID 605781, 15 pages, 2012.

[19] H. K. Nashine, Z. Kadelburg, and S. Radenović, "Common fixed point theorems for weakly isotone increasing mappings in ordered partial metric spaces," Mathematical and Computer Modelling. In press.

[20] S. Oltra and O. Valero, "Banach's fixed point theorem for partial metric spaces," Rendiconti, vol. 36, pp. 17-26, 2004.

[21] O. Valero, "On Banach fixed point theorems for partial metric spaces," Applied General Topology, vol. 6, no. 2, pp. 229-240, 2005.

[22] B. Samet, M. Rajović, R. Lazović, and R. Stoiljković, "Common fixed point results for nonlinear contractions in ordered partial metric spaces," Fixed Point Theory and Applications, vol. 2011, 71 pages, 2011.

[23] A. C. M. Ran and M. C. B. Reurings, "A fixed point theorem in partially ordered sets and some applications to matrix equations," Proceedings of the American Mathematical Society, vol. 132, no. 5, pp. 1435-1443, 2004.

[24] M. Filipović, L. Paunović, S. Radenović, and M. Rajović, "Remarks on 'Cone metric spaces and fixed point theorems of T-Kannan and T-Chatterjea contractive mappings'," Mathematical and Computer Modelling, vol. 54, no. 5-6, pp. 1467-1472, 2011.

[25] S. G. Matthews, "Partial metric topology," Research Report 212, Deptartment of Computer Science, University of Warwick, Warwick, UK, 1992. 
[26] S. Romaguera, "A Kirk type characterization of completeness for partial metric spaces," Fixed Point Theory and Applications, vol. 2010, Article ID 493298, 6 pages, 2010.

[27] S. Romaguera and O. Valero, "A quantitative computational model for complete partial metric spaces via formal balls," Mathematical Structures in Computer Science, vol. 19, no. 3, pp. 541-563, 2009.

[28] S. Oltra, S. Romaguera, and E. A. Saánchez-Pérez, "Bicompleting weightable quasi-metric spaces and partial metric spaces," Rendiconti del Circolo Matematico di Palermo, vol. 51, no. 2, pp. 151-162, 2002.

[29] D. Paesano and P. Vetro, "Suzuki's type characterizations of completeness for partial metric spaces and fixed points for partially ordered metric spaces," Topology and its Applications, vol. 159, pp. 911920, 2012.

[30] S. J. O’Neill, “Two topologies are better than one,” Tech. Rep., University of Warwick, Coventry, UK, 1995.

[31] J. R. Morales and E. Rojas, "Cone metric spaces and fixed point theorems of T-Kannan contractive mappings," International Journal of Mathematical Analysis, vol. 4, no. 1-4, pp. 175-184, 2010.

[32] G. E. Hardy and T. D. Rogers, "A generalization of a fixed point theorem of Reich," Canadian Mathematical Bulletin, vol. 16, pp. 201-206, 1973.

[33] G. S. Jeong and B. E. Rhoades, "Maps for which $F(T)=F\left(T^{n}\right)$," Fixed Point Theory and Applications, vol. 6, pp. 87-131, 2005. 


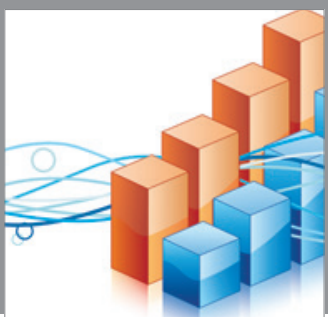

Advances in

Operations Research

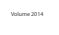

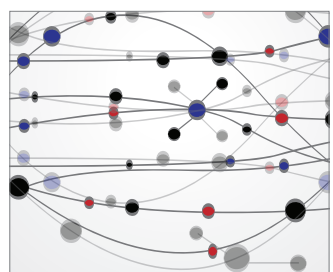

\section{The Scientific} World Journal
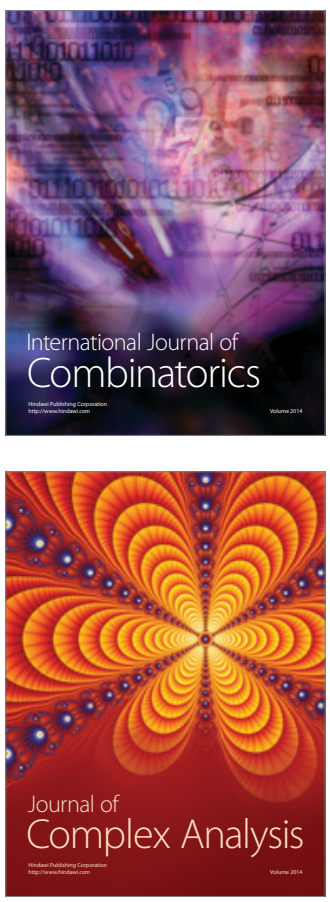

International Journal of

Mathematics and

Mathematical

Sciences
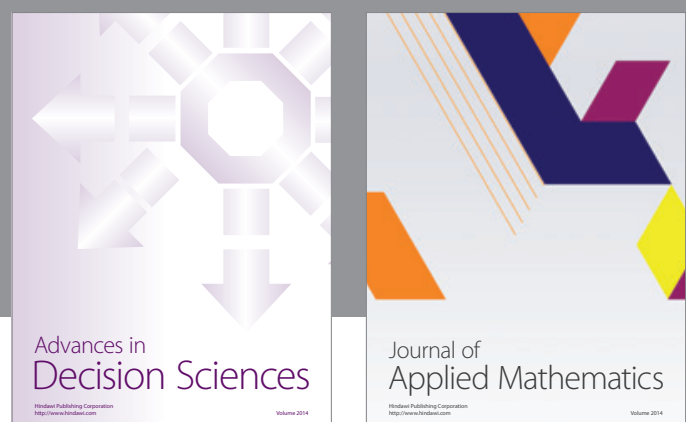

Journal of

Applied Mathematics
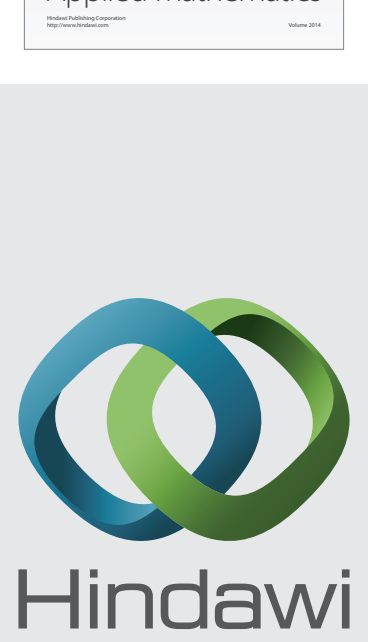

Submit your manuscripts at http://www.hindawi.com
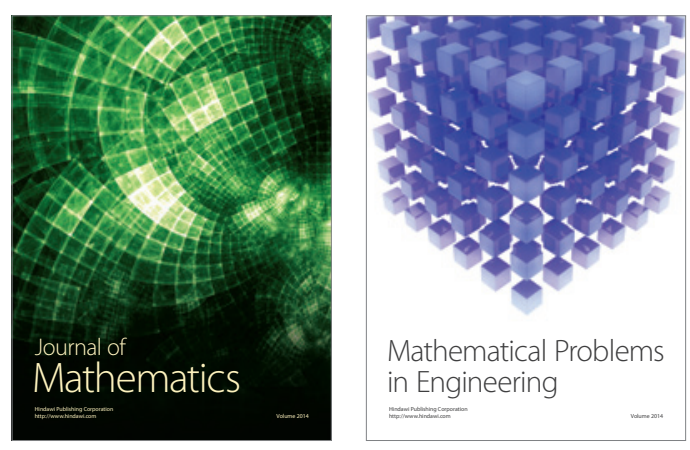

Mathematical Problems in Engineering
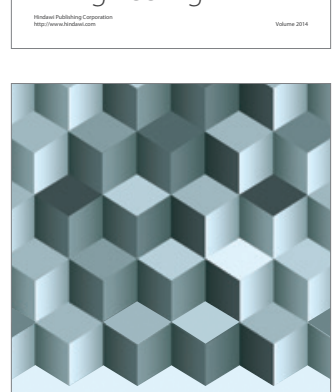

Journal of

Function Spaces
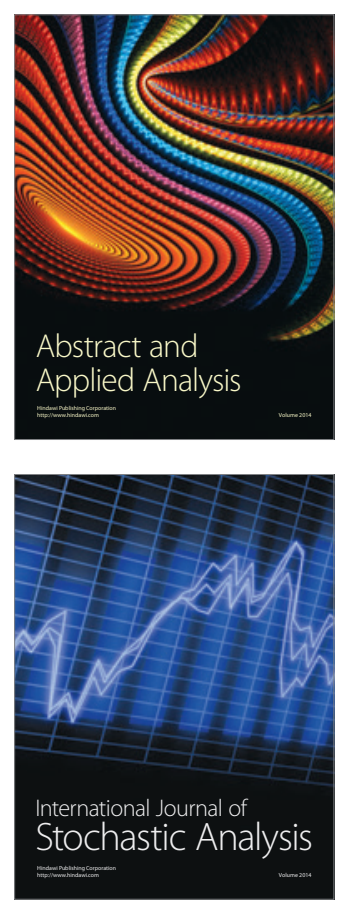

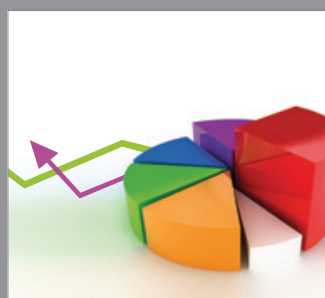

ournal of

Probability and Statistics

Promensencen
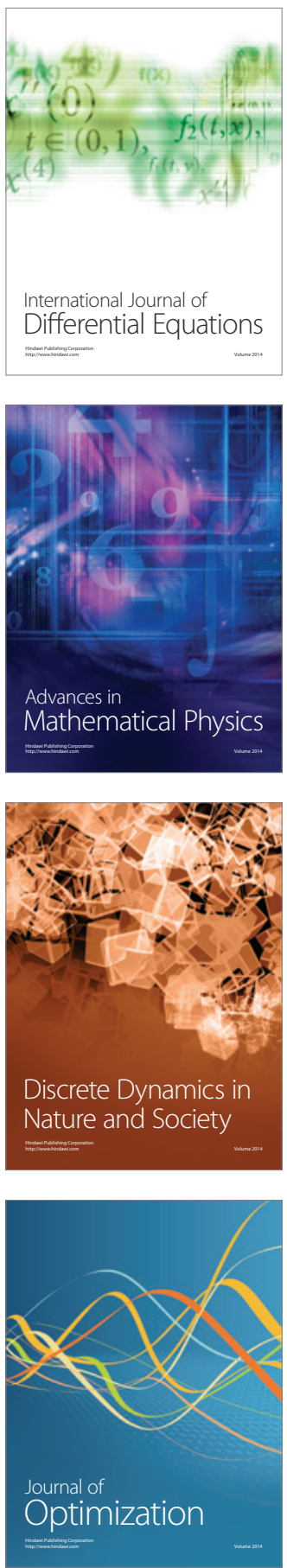